\title{
Cyberliteratures: a global perspective
}

\author{
Dolores Romero López
}

Published online: 29 September 2009

(C) Akadémiai Kiadó, Budapest, Hungary 2009

Globalization is a process of enormous proportions that alters and reconstructs the cultural map of the world by introducing new ways of creating, investigating and teaching in every area of knowledge. The electronic resources available to us necessarily modify the way we think and act. In view of the double process of globalization and digitalization underway at the start of the twenty-first century, the ICLA/AICL created, in the year 2005 and with the support of its President, Dr. Tania Franco Carvalhal, the Research Committee on Comparative Literature in Digital Age (CLDA).

The general aim of this Committee is to study the relationships of interference, displacement and intertextuality in hypermedia among different literatures in order to develop a clearer picture of new supports for transliterary and plural identities. The change of paradigm from text to hypertext involves an epistemological change in the study of new personal and national identities. The binary schema that for so long prevailed within the core of comparative studies has been devaluated, and it is being increasingly replaced by the possibilities offered by hypermedia, possibilities related to both epistemological perspectives and new media technology, and also to the fact that hypermedia considers alternative forms of expression and recognises differences.

The first step of the Research Committee was to highlight the need for the incorporation of new media technology and the epistemological potential of hypertext into every aspect of the field and discipline of Comparative Literature. The Committee strives to achieve, as a major objective, the consolidation of a research network on Comparative Literatures and e-Humanities learning. Placing identity issues at the centre of the debate, the Committee tries to avoid classical universalisms as much as all that is reductive and binary.

Dialogism and mobility in literatures may be particularly well represented by a hypertextual model. In fact, an open and creative system is needed, and not a closed, linear one, since we consider that the study of literature is a re-reading/re-writing activity and readers are makers of meaning. Nowadays, the invading metaphor of the network represents a relational model that creates links: literary texts become a bundle of possible

D. Romero López $(\bowtie)$

Departamento de Filología Española II (Literatura Española), Facultad de Filología (Edificio D), Universidad Complutense de Madrid, Despacho 1/331, Ciudad Universitaria s/n, 28040 Madrid, Spain e-mail: doloresromerolopez@gmail.com 
relations, through which the researcher (reader, student, teacher) can move according to their needs.

In order to develop research about this change of paradigm, an international conference entitled Literatures from Text to Hypertext was held at the Universidad Complutense, Madrid, Spain, in September 2006. The conference theme consisted of the challenges brought about by the change of paradigm in the different literatures, their dissemination, pedagogical aspects and their potential for use, focusing on both epistemological and new media technology perspectives. Two questions were posed: (1) How e-research and e-practices could be used by Comparative Literatures and (2) Which conceptual model could be selected to elaborate didactic/pedagogical and dissemination strategies. The results were published in two volumes: Literatures in the Digital Age: Theory and Praxis ${ }^{1}$ and Literatures in Digital Age. ${ }^{2}$

Three main objectives can be pointed out within the search for methodological solutions to the problems involved in the process from text to hypertext. Firstly, the new literary consciousness that hypertext generates; secondly, the effects of hypertext considered as a source text by researchers, teachers, students, and the general public; and finally, the scope of the plurality opened by hypertext models, in stark contrast with the binary perspective of traditional comparison.

The different members of the Research Committee on Comparative Literatures in the Digital Age have again come together in order to offer their latest research in a special issue of the journal Neohelicon. We are now more convinced than ever before that the literatures of the future will be hypertextual or hypermedia, or will not come to be at all. We are perfectly aware that the use of an electronic support is not in itself a guarantee of literary or didactic innovation. In fact there are already too many digital pages that are nothing more than that: digitalisation of content. This is not sufficient. The novelty will be found in the conceptual framework within which we put the resources and materials into action, in the cognitive system that we intend to activate. The philologist, the humanist, she or he who adopts a comparative perspective, the creator, must all "find themselves a home" within this virtual space, no matter how high the price of preparing content may be. As scholars of the literatures, we have an imminent additional function: to shift our ideas into the reticular cognitive format of the Web.

The volume the reader now has in hand covers different aspects of the cyberliteratures. George Landow discusses in his article the nature of cybernonfiction, and presents a number of examples of the theory and practice of nonfiction in e-space. Dirk Van Hulle examines in his article on Digital Philology the dynamics of incompletion that characterize many writings by twentieth-century authors. He investigates the possibilities of visualising (1) switches, (2) shuffles and (3) shifts in modern multilingual manuscripts with digital philological tools. In Dolores Romero's article on analogue and hypermedia texts in Hispanic Literatures, she explores some of the characteristics attributable to digital literature-collective experimentation and the rupture of narrative linearity-and ways of approaching digital works in relation to three reading pathways: linear, helicoid and rhizomatic.

The central section of the volume is made up of a set of articles which analyse different aspects of online literary creation. In this respect, Alexandra Saemmer explains how authors and readers deal with the lability of the electronic device. In her opinion, digital artists are

\footnotetext{
${ }^{1}$ Sanz, A., \& Romero, D. (Eds.). (2007). Literatures in the digital age: Theory and praxis. Newcastle: Cambridge Scholar Pressing.

${ }^{2}$ Romero, D., \& Sanz, A. (Eds.). (2008). Literaturas del texto al hipermedia. Barcelona: Anthropos.
} 
given four options when dealing with the lability of the electronic device: the "aesthetics of the auteur-roi", the "aesthetics of the ephemeral", the "aesthetics of re-enchantment" and the "aesthetics of surface." Next, Alckmar Dos Santos selects an example of Brazilian digital literature in order to re-think the strategies of anthropophagy. In his detailed analysis of Rui Torres' work Amor de Clarice, he discusses the instigating experience of seeing how Rui allows us to better understand mechanisms, elements, and processes by means of anthropophagic appropriations (or contrapositions) of elements such as the following: the appropriation of written and printed literature by digital medium creation; of the Brazilian literary tradition by the Portuguese; of (printed) prose by (digital) poetry; of words by images (fixed or on video); of the comfortable sequence in which one goes through the work by the (quick) instability of the signifiers. Marie-Thérèse Abdel-Messih analyses another important aspect of Arabian digital narrative: The publication of popular Egyptian autobiographical narrative weblogs. She poses several examples in which the impact of media digitalisation promotes the hyper quality that subverts linearity in dominant discourse. Ziva Ben-Porat's article shows an experience of how the Western canon is instantiated in Hebrew Digital Media. Her essay focuses on the methodological problems of mapping a national cultural memory from the angle of the use it makes of western literary heritage. She uses three cultural “memes" (Don Quixote's tilting the windmills, Hamlet's contemplation of suicide, and Romeo and Juliet as the ultimate lovers) as the most appropriate type of matter for constructing multimedia hypertext educational threads.

The last two articles focus on other thought provoking aspects of the digitalization of literatures: Hans-Joachim Backe' article discusses the future role of narrative computer games in the academic canon, and Amelia Sanz and María Goicoechea focus on the new rituals of reading which are developing functional models for adjusting our print reading strategies to the didactic digital domain.

During these first years of the twenty-first century, we perceive that modernity finds itself in the face of a new crusade, the centre of which is a complex subject, with the load of progress already assimilated. These mutating subjects are the fruit of globalisation, which has generated an ethereal, reticular and dislocated individuality. Nowadays the search for identity has become a determining social factor. The subject now needs interfaces and networks in order to compose his or her own identity. The great feature of our times consists of ephemeral, hybrid identities created in the surroundings of the computer, an essential element of our lives, thanks to which we relate to others, think and build our social relationships. As readers and critics, we still look forward to the universal normalisation and generalisation of digital literature that will allow us to reflect on, and discuss, the proposals of its creators, which, doubtless, will represent a Weltanschauung of our time.

From what has been said up to now, it seems that the issues mentioned have contributed to encouraging the idea that we are facing something new, a cognitive change similar to the one brought about by the printing press at the end of the fifteenth century. Back then, the phenomenon of a greater number of copies of a work reaching the hands of its readers was accompanied by the conquest of a New World; nowadays too, a New Space is appearing (an intangible, endless, infinite one) for humanity, based on diversity and dispersion. Both periods, thanks to the collaboration between technology and literature, increase and change (quantitatively and qualitatively) information, communication and culture. In addition, both books on paper and virtual pages are becoming instruments for managing the collective memory, thus developing the progress of the history of humanity (earth, stone, papyrus, paper, digits). 